\title{
Outcome of basic life support training among primary school students in Southeast Asia
}

\author{
Chananthon Suwanpairoj', Thanakorn Wongsombut ${ }^{1}$, \\ Kittipitch Maisawat', Nita Torod' ${ }^{1}$, Ampaka Jaengkrajan', \\ Natchaya Sritharo ${ }^{1}$, Nattikarn Atthapreyangkul ${ }^{1,2}$, \\ Borwon Wittayachamnankul ${ }^{1,2}$ \\ ${ }^{1}$ Faculty of Medicine, Chiang Mai University, Chiang Mai, Thailand \\ ${ }^{2}$ Department of Emergency Medicine, Chiang Mai University, Chiang Mai, Thailand
}

Objective This study aimed to evaluate how BLS courses affect primary school students' knowledge, attitudes, and life support skills; investigate how medical students' knowledge and competence in teaching BLS can improve by serving as instructors.

Methods This experimental study was conducted in a rural primary school. First-year medical students conducted a BLS course for grade 4 and 5 primary school students with a 6-7:1 ratio of trainees-to-trainer. All trainers had completed a BLS course before the course. This 3.5-hour simulation-based course covered chest compressions and automated external defibrillator use. The pre- and post-course assessments included multiple choice questions toward BLS, practical skills test, and attitude test. For medical students, evaluation was conducted by attitude test, both pre- and post-teaching.

Results The mean pre- and post-test scores increased from $5.74 \pm 0.10$ to $9.43 \pm 0.13(P<0.01)$. The increase in the scores was the same for both the students and the teachers $(3.05 \pm 0.60$ vs. $3.68 \pm 0.16, P=0.33$ ). After the course, more than $90 \%$ of the students could perform all the procedures involved in BLS and automated external defibrillation. Medical students showed an improved understanding of CPR and confidence in performing and teaching CPR (both, $\mathrm{P}<0.01$ ).

Conclusion Primary school students can learn how to perform BLS through simulation-based learning. Simulation-based training can improve their attitude and provide them with knowledge and crucial skill sets, improving their confidence in performing BLS. Furthermore, teachers' attitudes and confidence toward CPR improved after teaching CPR.

Keywords Schools; Simulation training; Cardiopulmonary resuscitation; Medical education

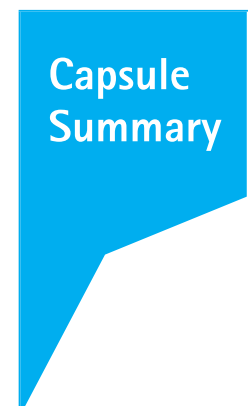

What is already known

Teaching basic life support in primary schools improves student knowledge, skills, and attitudes.

What is new in the current study

In this study, primary school students had inadequate safety awareness during cardiopulmonary resuscitation; medical students showed an improved understanding of CPR and confidence in performing and teaching CPR.
elSSN: 2383-4625

Received: 9 November 2019

Revised: 31 December 2019

Accepted: 31 December 2019

Correspondence to:

Borwon Wittayachamnankul

Department of Emergency Medicine,

Faculty of Medicine, Chiang Mai

University, 110 Inthawaroroj, Sriphoom,

Chiang Mai 50200, Thailand

E-mail: borwon.witt@cmu.ac.th

ORCID

https://orcid.org/0000-0003-3465-5534

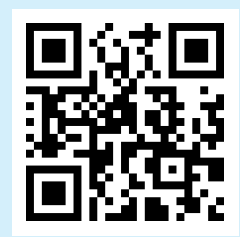

How to cite this article:

Suwanpairoj C, Wongsombut T, Maisawat $\mathrm{K}$, Torod N, Jaengkrajan A, Sritharo N, Atthapreyangkul N, Wittayachamnankul B. Outcome of basic life support training among primary school students in Southeast Asia. Clin Exp Emerg Med 2020;7(4):245249. https://doi.org/10.15441/ceem.19.095

This is an Open Access article distributed under the terms of the Creative Commons Attribution Non-Commercial License (https:// creativecommons.org/licenses/by-nc/4.0/). 


\section{INTRODUCTION}

Bystander knowledge of basic life support (BLS) is essential for improving the survival rate of sudden cardiac arrest. ${ }^{1,2}$ Around $15 \%$ of bystanders in Thailand perform BLS upon encountering a collapsed patient. ${ }^{3}$ In many countries, such as USA ${ }^{4}$ and Norway, ${ }_{1}^{5}$ BLS is a compulsory part of school education. Evidence supports that teaching BLS in primary school improves the skill and knowledge of students..$^{6-9}$ However, there are no previous studies showing the benefit of teaching BLS as part of the compulsory curriculum in South East Asian schools, especially in primary education. The potential of children to learn BLS may drive policies to establish cardiopulmonary resuscitation (CPR) teaching starting from the primary schools. Hence, this study aims to report the influence of BLS courses on the knowledge, attitudes, and life support skills of primary school students; it also aims to improve certain aspects of medical professionalism among medical students acting as instructors.

\section{METHODS}

This experimental study was performed at Ban Rim Tai School, a rural primary school consisting of 1,057 students, in Chiang Mai Province. The protocol was approved by the Institutional Ethical Committee of the Faculty of Medicine, Chiang Mai University (EME-2560-04799). No informed consent was required as this study was waved for educational purpose. The BLS course was conducted by first-year medical students who had previously completed BLS provider and instructor courses. A curriculum was prepared for upper primary school students using the learn-andplay concept. This was performed by creating cartoon characters to promote child learning, and by utilizing simulation techniques in both skills and test stations. The 3.5-hour modified BLS course emphasized adult chest compression-only CPR and the use of automated external defibrillator which was taught both theoretically and practically. This course was modified from a standard 4-hour BLS provider course, which is the conventional BLS course in Thailand provided by the Thai Resuscitation Council. However, this course was different from the standard course due to its exclusion of courses on rescue breathing and foreign body aspiration. The courses and tests were designed by medical students, senior BLS instructors, and specialists in primary school education. Each course was closely monitored, controlled, and advised by experienced instructors who were doctors and nurses. Students in grades 4 and 5 participated in this course with the ratio of trainee-to-trainer of 6-7:1. Four courses were conducted in the school gymnasium. The pretest and posttests, each consisting of
14 four-multiple choice questions (Supplement 1), were taken by both students and school teachers before and immediately after the teaching sessions. However, the skill and attitude tests were performed only by primary school students immediately after the teaching sessions. The skill test of one-rescuer CPR and automated external defibrillator was conducted by a medical student instructor using a standard checklist to evaluate the steps and quality of CPR (Supplement 2). Additionally, the attitude was evaluated using a 5-point Likert scale asking 11 questions. The instructors also answered a questionnaire before and after teaching the BLS course using a 5-point Likert scale. Three questions were asked regarding the following components: 1) understanding rationale, steps, and methods of BLS, 2) confidence in performing $\mathrm{BLS}$, and 3) confidence in teaching BLS.

Data are presented as percent, mean and standard deviation. Statistical analysis was performed using IBM SPSS Statistics ver. 21.0 (IBM Corp., Armonk, NY, USA). Score comparisons were performed using Student t-test, and $\mathrm{P}<0.01$ was considered statistically significant.

\section{RESULTS}

Three hundred and thirteen students and 23 teachers participated in this course. This included 166 grade 5 students (53.0\%) and the remainder who were in grade 4 . The average age of students in grade 4 and grade 5 was 9.4 and 10.7 years, respectively. The students' and teachers' knowledge regarding BLS significantly increased at the end of training. Although the students had lower mean scores than the teachers in both the pretest (5.74 vs. 9.23, $\mathrm{P}<0.01$ ) and posttests (9.43 vs.12.29, $\mathrm{P}<0.01$ ) results (Fig. 1), the

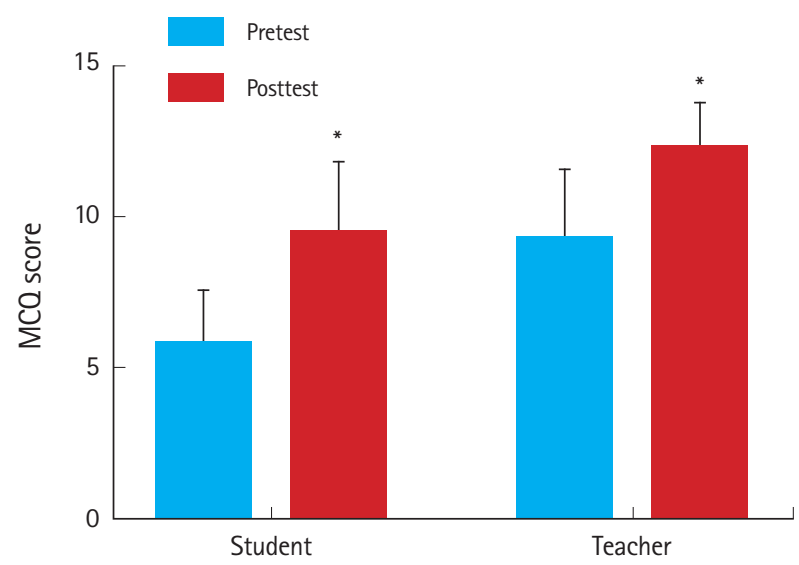

Fig. 1. Comparison of pretest and posttest multiple choice questions (MCO) score. There was an increase in posttest scores both in students and teachers. ${ }^{*} P<0.01$ vs. pretest. 
difference between the two groups in terms of pretest and posttest scores was the same (3.05 vs. $3.678, P=0.33$ ) (Table 1). Additionally, almost all the essential CPR skills were performed correctly by the students, except for 'scene safety' and 'clear patient for shock' procedures (Table 2). At the end of the training, most of the students believed that BLS was essential, and that they could correctly perform BLS and provide bystander assistance to victims who collapse (Table 3).

Fifteen of the 23 medical students who were instructors of the BLS course answered the questionnaire, and responded that they had significantly increased their understanding of BLS $(P<0.01)$,

Table 1. Pretest and posttest of multiple choice questions score ( $\max =14$ points)

\begin{tabular}{lccc}
\hline & Student $(\mathrm{n}=313)$ & Teacher $(\mathrm{n}=23)$ & P-value \\
\hline Pretest score & $5.74 \pm 0.10$ & $9.23 \pm 0.49$ & $<0.01$ \\
Posttest score & $9.43 \pm 0.13$ & $12.29 \pm 0.32$ & $<0.01$ \\
Increase in score & $3.05 \pm 0.60$ & $3.68 \pm 0.16$ & 0.33
\end{tabular}

Values are presented as mean \pm standard deviation.

Table 2. Result of practical test after learning

\begin{tabular}{lc}
\hline Maneuver & Correct (\%) \\
\hline Scene safety & 78.3 \\
Detection of cardiac arrest & 92.0 \\
Call for help & 93.0 \\
Calling for automated external defibrillator & 89.5 \\
Hand position & 97.8 \\
Depth > 5 cm & 93.9 \\
Rate 100-120/min & 92.7 \\
Switch on automated external defibrillator & 96.5 \\
Attach pad to chest & 96.8 \\
Clear patient for analysis of rhythms & 99.7 \\
Clear patient for shock & 87.9 \\
Continual chest compressions & 97.5
\end{tabular}

confidence in performing BLS $(\mathrm{P}<0.01)$, and confidence in teaching $B L S(P<0.01)$ (Fig. 2).

\section{DISCUSSION}

Our data demonstrated that a BLS course consisting of lecture and practice components can improve primary school students' knowledge, while enhancing their skills and attitude towards CPR. Despite children having less strength than adults, they have the required psychomotor skills and are able to perform BLS after practice sessions. This correlated with many studies in Europe $\mathrm{e}^{7,8,10}$ and Australia, ${ }^{9}$ supporting that BLS and first-aid training can help develop the skill and knowledge of life support in children. More-

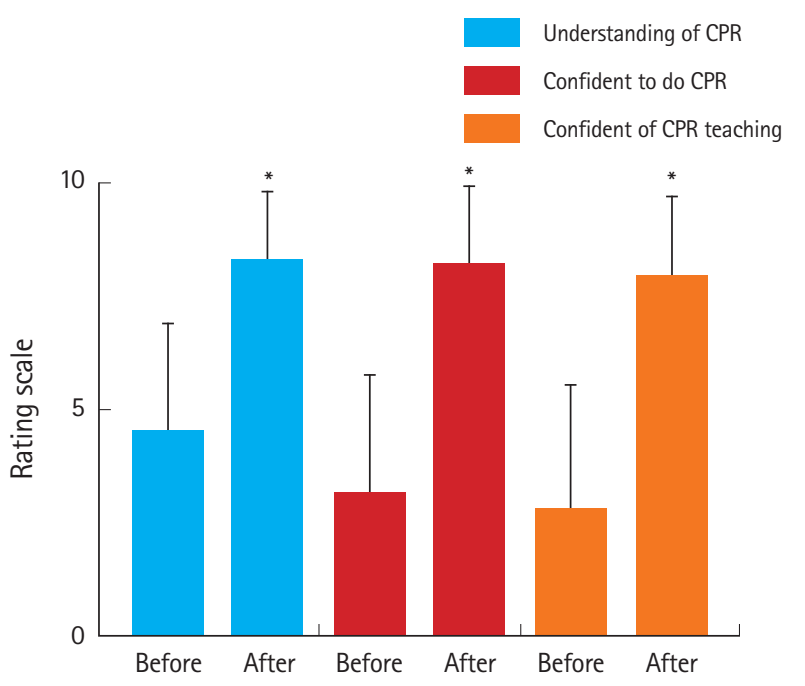

Fig. 2. Rating scale of medical students who are instructors of the basic life support (BLS) course before and after regarding understanding BLS, confidence to perform BLS, and confidence in teaching BLS. ${ }^{*} \mathrm{P}<0.01$ vs. before. CPR, cardiopulmonary resuscitation.

Table 3. Attitude of students after learning

\begin{tabular}{|c|c|c|}
\hline Attitude of students after learning BLS & Mean & Interpretation \\
\hline I think most people do not know the principles of BLS. & 3.67 & Agree \\
\hline CPR should be performed by those who have training. & 3.58 & Agree \\
\hline Everyone should be able to perform BLS. & 3.67 & Agree \\
\hline BLS is beneficial to self and the surrounding people. & 4.49 & Strongly agree \\
\hline The importance of BLS is appreciated. & 4.12 & Agree \\
\hline The training is practical in real life. & 4.54 & Strongly agree \\
\hline The obtained knowledge would last for years onward. & 4.48 & Strongly agree \\
\hline When encountering unconscious patients, I would be able to remain calm and follow the BLS steps correctly. & 4.23 & Strongly agree \\
\hline I can perform each step of BLS with confidence. & 3.95 & Agree \\
\hline I think I can teach other people how to do BLS correctly afterward. & 4.16 & Agree \\
\hline I need further training in first aid. & 4.29 & Strongly agree \\
\hline
\end{tabular}

Likert scale: 1.00-1.80, strongly disagree; $1.81-2.60$, disagree; $2.61-3.40$, neutral; $3.41-4.20$, agree; $4.21-5.00$, strongly agree. $\mathrm{BLS}$, basic life support; $\mathrm{CPR}$, cardiopulmonary resuscitation. 
over, this may cultivate children's confidence to help other victims. Although the teachers had higher pretest and posttest scores than students, the knowledge improvement of primary school students was not different from that of adults. This may be attributed to students having less experience than teachers, although the students had equal ability in learning BLS. This result correlated with a study in Hungary that showed that the age group was correlated with learning BLS. ${ }^{6}$ However, the sense of safety awareness among upper primary school students was inadequate, and this was reflected in students forgetting to perform safety awareness before helping and "clearing-beforeshocking". This defect of learning can be corrected by repeated learning of BLS in secondary school. Furthermore, most students correctly performed skill maneuvers, as they had physical strength; nonetheless, scene safety must be emphasized more because students were least concerned about scene safety.

From the learning pyramid, teaching others is the best way to gain a better understanding and knowledge on a subject. Medical students learned from this teaching process and consequently gained more confidence to perform BLS by themselves. Another study also showed improvement of resuscitation and teaching skills in medical students after teaching others. ${ }^{11}$ These skills are essential for medical professionals in the future. This study not only improved their knowledge and confidence to perform and teach BLS, but it also emphasized the importance of public health education to medical students.

This study had some limitations. First, this was a small study from one rural school. However, compulsory education in Thailand has the same curricula in all schools; hence, the data may be representative of primary school students in Thailand. Second, we did not collect baseline characteristics or factors associated with BLS knowledge of the students and school teachers such as gender, body mass index, education, previous BLS knowledge, or previous health education. Third, the students did not have a pretest of skills and attitudes, but almost all the students had no prior knowledge about BLS, as shown in the pretest. Additionally, the adapted multiple questions from the standard course were not validated by a standard method, and no subsequent reviews of the course were made to evaluate the skills and knowledge of the participants. Therefore, future studies should aim to review the knowledge retention of participants. Finally, the medical students were not assessed with a questionnaire before the course began, and this may contribute some bias to rating scale questions.

In conclusion, primary school students have the potential to learn BLS by using a simulation-based approach; the training improves their attitude and provides them with knowledge and crucial skill sets, which improves their confidence in performing BLS.

\section{CONFLICT OF INTEREST}

No potential conflict of interest relevant to this article was reported.

\section{ACKNOWLEDGMENTS}

The authors gratefully acknowledge the first-year medical student, group XX9 for their role in creating and organizing this project. We acknowledge Dr. Kamphee Sruamsiri for technical editing, language editing, and proof reading. We would also like to thank the Faculty of Medicine, Chiang Mai University for funding this study.

\section{SUPPLEMENTARY MATERIAL}

Supplementary materials are available from: $\mathrm{https}: / /$ doi.org/10.15441/ ceem.19.095.

\section{REFERENCES}

1. Agerskov M, Nielsen AM, Hansen CM, et al. Public access defibrillation: great benefit and potential but infrequently used. Resuscitation 2015;96:53-8.

2. Eftestol T, Sunde K, Steen PA. Effects of interrupting precordial compressions on the calculated probability of defibrillation success during out-of-hospital cardiac arrest. Circulation 2002;105:2270-3.

3. Ong ME, Shin SD, De Souza NN, et al. Outcomes for out-ofhospital cardiac arrests across 7 countries in Asia: The Pan Asian Resuscitation Outcomes Study (PAROS). Resuscitation 2015;96:100-8.

4. Bogle B, Mehrotra S, Chiampas G, Aldeen AZ. Assessment of knowledge and attitudes regarding automated external defibrillators and cardiopulmonary resuscitation among American University students. Emerg Med J 2013;30:837-41.

5. Kanstad BK, Nilsen SA, Fredriksen K. CPR knowledge and attitude to performing bystander CPR among secondary school students in Norway. Resuscitation 2011;82:1053-9.

6. Banfai $B$, Pek E, Pandur A, Csonka $H$, Betlehem J. 'The year of first aid': effectiveness of a 3-day first aid programme for 714-year-old primary school children. Emerg Med J 2017;34: 526-32.

7. Calicchia S, Cangiano G, Capanna S, De Rosa M, Papaleo B. Teaching life-saving manoeuvres in primary school. Biomed Res Int 2016;2016:2647235.

8. Lubrano R, Romero $S$, Scoppi $P$, et al. How to become an under 11 rescuer: a practical method to teach first aid to prima- 
ry schoolchildren. Resuscitation 2005;64:303-7.

9. Wilks J, Kanasa H, Pendergast D, Clark K. Emergency response readiness for primary school children. Aust Health Rev 2016; 40:357-63.

10. Toner $\mathrm{P}$, Connolly $\mathrm{M}$, Laverty $\mathrm{L}, \mathrm{McGrath} \mathrm{P}$, Connolly $\mathrm{D}, \mathrm{Mc}-$ Cluskey DR. Teaching basic life support to school children using medical students and teachers in a 'peer-training' model: results of the 'ABC for life' programme. Resuscitation 2007; 75:169-75.

11. Beck $S$, Meier-Klages $V$, Michaelis $M$, et al. Teaching school children basic life support improves teaching and basic life support skills of medical students: a randomised, controlled trial. Resuscitation 2016;108:1-7. 